\title{
Da inversão do paradigma teórico-prático até a atual concepção da paz como requisito vital para o pleno desfrute dos direitos humanos em igualdade
}

The reversal of the theoretical-practical paradigm for the current conception of peace as a vital requirement for the full enjoyment of all human rights by all

\author{
ALEX SANDER XAVIER PIRES' \\ asxpires@gmail.com \\ GALILEU - REVISTA DE DIREITO E ECONOMIA · e-ISSN 2184-1845 \\ Volume XX $\cdot 1^{\text {st }}$ January Janeiro $-30^{\mathrm{TH}}$ June Junho $2019 \cdot$ pp. 78-98 \\ DOI: ??? \\ Submitted on April 17 th $2019 \cdot$ Accepted on May $28^{\text {th }}, 2019$ \\ Submetido em 17 de Abril, 2019 - Aceite a 28 de Maio, 2019
}

RESUmo Passado um século desde a assinatura do Tratado de Versalhes e pouco mais de setenta anos da aprovação da Declaração Universal dos Direitos do Homem, muito se questiona qual o tratamento científico a ser dispensado a paz, uma vez que não mais se aceita a simples oposição a guerra, menos ainda quando analisada no impreciso contexto de valoração pela justiça. Assim, pretende-se apresentar o atual sistema no âmbito das Nações Unidas voltado a reta missão de formação de uma consciência humana, enquanto amadurecimento moral, de que a paz, para além da cessação de todas as hostilidades, indica um estado permanente, universal e perpétuo, que deve acompanhar os seres humanos nas relações entre si.

Palavras-chave Paz. Cultura de Paz. Direito à Paz. Maturidade moral.

ABSTRACT After a century since the Treaty of Versailles and just over seventy years after the adoption of the Universal Declaration of Human Rights, much is being asked about the

1 Pós-Doutor em Direito (Portugal), Doutor em Ciências Jurídicas e Sociais (Argentina), Doutor em Ciência Política (Brasil). Fundador do Projeto Pensar a Justiça. Professor universitário - Universidade Autónoma de Lisboa (UAL). Investigador no Centro de Investigação Ratio Legis/UAL. Secretário-Geral do ECII - Ethical \& Compliance International Institute. Colaborador no Centro de Investigação CEDIS/UNL. Advogado. 
Da inversão do paradigma teórico-prático até a atual concepção da paz como requisito vital...

ALEX SANDER XAVIER PIRES

GALILEU - e-ISSN 2184-1845 - Volume XX - Issue Fascículo 1 - $1^{\text {st }}$ January Janeiro - 30 th June Junho $2019 \cdot$ pp. 78-98

scientific treatment about the peace, nowadays there is not accepted the only treatment as the opposition against the war, neither by the imprecise concept of the justice. Thus, this text intends to present the current system within the framework of the United Nations aimed at the formation of a human conscience, while moral maturity, that peace indicates a permanent, universal and perpetual sense, beyond the cessation of all hostilities, which must accompany human beings in their relations with one another.

KEYWORDS Peace. Culture of Peace. Right to Peace. Moral maturity.

\section{Introdução}

O ano de 2019 é emblemático para [re]discussão dos elementos constitutivos da paz num mundo que anseia por fraternidade, e para reconstrução das bases normativas que justificaram ideologicamente a inversão do eixo constitucional para que os Estados passassem a adotar políticas, públicas e de relações internacionais de cooperação, dedicadas ao favorecimento do acesso dos indivíduos aos bens sociais, especialmente os primários - aqui reconhecidos aqueles garantidos pelas liberdades fundamentais, indutivos dos consequentes direitos em responsabilidade que lhes são imanentes.

O momento é oportuno porque traz à reflexão, na era da "constituição dos modernos", inúmeros fatos históricos intimamente relacionados com a construção ou manutenção da paz no âmbito da humanização das relações, reconstrução das relações de poder e concepção normativa de garantias assentadas na restrição de direitos em oposição a deveres, como se observa nos 360 anos do Traité de Paix des Pyrénées ${ }^{2}$ (1659), 330 anos da English Bill of Rights ${ }^{3}$ (1689), 230 anos da Déclaration de Droit de l'Homme et du Citoyen ${ }^{4}$ (1789), 230 anos da U.S. Bill of Rights $^{5}$ (1789), e pouco mais de 70 anos da Universal Declaration of Human Rights ${ }^{6}$ (1948).

2 Documento integrante do sistema denominado "Paz de Vestfália". Disponível em: <http://mjp.univ-perp.fr/ traites/1659pyrenees.htm >, último acesso em 28/05/2019.

3 Disponível em: <http://avalon.law.yale.edu/17th_century/england.asp>, último acesso em 28/05/2019.

4 Disponível em: <https://www.conseil-constitutionnel.fr/le-bloc-de-constitutionnalite/declaration-des-droits-de-l-homme-et-du-citoyen-de-1789>, último acesso em 28/05/2019.

5 As dez primeiras Amendments compõem a U.S. Bill of Rights - disponível em: <http://avalon.law.yale.edu/18th_ century/rightsı.asp\#1>, último acesso em 28/05/2019 -, e foram concebidas no âmbito do Primeiro Congresso como consta da Resolução de 4 de março de 1789 - disponível em: <http://avalon.law.yale.edu/18th_century/ resolu02.asp >, último acesso em 28/05/2019.

6 Disponível em: <https://www.un.org/en/universal-declaration-human-rights/>, último acesso em 28/05/2019. 
Longe de constituir apenas memória histórica, estes documentos, dentre tantos, inspiram e renovam o fenômeno contemporâneo de fortalecimento da paz como propósito dos povos e dos Estados em comunidade internacional desde a centenária marca de cem anos posta pelo Tratado de Versalhes ${ }^{7}$ e, mais proximamente, com a concepção de um sistema tendente a firmar a paz enquanto direito fundamental no âmbito interno dos constitucionalismos, e universal com força de requisito vital para o pleno desfrute dos direitos humanos em igualdade para todos, como se depreende da Agenda sobre a paz da Assembleia Geral das Nações Unidas no $73 .^{\circ}$ Período de Sessões.

A dita Agenda sobre a paz e o movimento de elevação da paz ao nível de direito fundamental também é fruto de movimentos históricos alinhavados para reconstruir os fundamentos teóricos e, principalmente, induzir na mente humana o sentimento de que a paz é muito mais que a simples oposição a guerra e vai além da mera cessação das hostilidades, o que se percebe desde a criação da Carta das Nações Unidas que, ao deflagrar o sistema de direitos humanos, assentou as bases para formulação da cultura de paz indutiva do novo sentimento.

A nova formulação do sentimento de paz basilar da cultura de paz pode ser lida, portanto, desde a Carta das Nações Unidas quando a paz foi alçada a Propósito [rectius, objetivo a ser alcançado em conjunto com a segurança, ambas em nível internacional] e pela universalidade de direitos imanentes aos indivíduos e oponíveis a todos, principalmente aos Estados, nos limites da Declaração Universal dos Direitos Humanos.

Neste sentido, há 69 anos, em 1950, foi aprovada a Resolução referente ao programa de 20-anos para alcançar a paz através das Nações Unidas (A/RES/5/494), o que deflagrou uma onda de Declarações sobre o sistema de paz, dentre os quais a Declaração sobre a preparação das sociedades para viver em paz (A/RES/33/73), a Declaração dos direitos dos povos à paz (A/RES/39/11), a Declaração - e o Programa de ação - sobre a cultura de paz (A/ RES/53/243), e a Declaração sobre o Direito à paz (A/RES/71/189).

Assim, o presente texto pretende apresentar os quatro passos do sistema de paz das Nações Unidas, partindo da inversão do paradigma teórico-prático concebido no âmbito da "constituição dos modernos" até a atual concepção da paz como requisito vital para o pleno desfrute dos direitos humanos em igualdade para todos.

7 O Tratado de Versalhes, aqui referido, é tratado de paz firmado com a Alemanha em vias de por termo à Primeira Guerra Mundial. Disponível em: <http://www.loc.gov/law/help/us-treaties/bevans/m-ustooooo2-0043.pdf>, último acesso em 28/05/2019. 


\section{Teorizando um paradigma}

No âmbito das discussões sobre a limitação do poder político e da garantia de acesso a
direitos oponíveis a deveres ${ }^{8}$ traço característico $^{9}$ da constituição dos modernos ${ }^{10}$, desde o
século XVII (para não se ir muito longe na História da humanidade), observa-se a reconfi-
guração ${ }^{11}$ da tensa dualidade polarizada entre vícios e virtudes numa concepção entre bem
e mal, bom e mau, justo e injusto, em que a paz é concebida como o oposto a guerra em

8 "....] os modernos formalizaram de maneira extrema a problemática da forma de governo, resolvendo-a finalmente por uma técnica de atribuição de competências baseada no pressuposto que a questão do governo se exaure totalmente no plano das relações dos poderes públicos - por exemplo, no positivismo do século XIX, entre os órgãos do Estado -, considerados distintos e separados das forças sociais, dos conflitos e dos equilíbrios sociais"; tradução livre e pessoal de: "[...] los modernos han formalizado de manera extrema la problemática de la forma de gobierno, resolviéndola finalmente en una técnica de atribución de competencias, basada en el presupuesto de que la cuestión del gobierno se agota totalmente en el plano de las relaciones entre los poderes públicos - por ejemplo, en el positivismo decimonónico, entre los órganos del Estado -, tornados como distintos y separados de las fuerzas sociales, de los conflictos y de los equilibrios sociales" (FIORAVANTI, Maurizio - Constitución: De la Antigüedad a Nuestros Días. Madrid: Editorial Trotta, 2001, p. 16).

9 Reconhece-se que existem tantos constitucionalismos quanto são os estados constitucionais, de sorte que o historicismo construído por detrás das ordens constitucionais de cada Estado soberano marca as características individuais de cada sistema. No entanto, desde a Magna Carta Inglesa, no século XIII, observa-se a instauração de sistemas, cada um a seu tempo, com características comuns de limitação do poder político na Constituição e garantia de direitos com a respectiva oposição de deveres, inclusive contra o próprio Estado.

10 A opção pelo assentamento teórico-cronológico concebido pela "constituição dos modernos" traz a colação a construção de Maurizio Fioravanti que distribui a leitura constitucional em três fases: a constituição dos antigos, a constituição feudal e a constituição dos modernos, em que, esta, "caracteriza-se pela força jurídica debruçada sobre a concessão de direitos antepostos a deveres, bem como a regulamentação da separação dos poderes, arquitetados para fins de limitação da soberania e de estruturação e equilíbrio do Estado" (PIRES, Alex Sander Xavier; TRINDADE, Carla Dolezel; FILHO, Simão Aznar - Constitucionalismo Luso-Brasileiro: leitura normativa no âmbito do domínio da lei e da humanização das relações. Rio de Janeiro: Pensar a Justiça, 2017, p. 21), como se depreende de: "[...] Não há que se falar, como óbvio, da existência de uma constituição efetiva [dos antigos], senão daquela constituição que continuamente é invocada pelos antigos como politeia o como res publica, ou seja, como critério de ordem e de medida das árduas relações políticas e sociais de seu tempo. Neste sentido, e sobre este plano, não há dúvida que existiu uma constituição dos antigos. Tal constituição obviamente não tem relação alguma com a constituição dos modernos. Os antigos não tinham nenhuma <<soberania〉> que limitar, nem, ademais, tinham pensado na constituição como norma, a norma que em tempo moderno seria chamada a separar os poderes e a garantir os direitos. Eles pensavam mais na constituição como uma exigência a satisfazer, como um ideal - ao mesmo tempo ético e político - a perseguir, que se fazia ainda mais forte - como vimos - nas fases de crises mais intensa, de mais clara separação política e social, como no caso da decadência da polis grega ou da mesma res publica romana"; tradução livre e pessoal de: "[...] No ya, como es obvio, de la constitución que existió efectivamente, sino de aquella constitución que continuamente es invocada por los antiguos como politeia o como res publica, es decir, como criterio de orden y de medida de las arduas relaciones políticas y sociales de su tiempo. En este sentido, y sobre este plano, no hay duda de que existió una constitución de los antiguos. Tal constitución obviamente no tiene relación alguna con la constitución de los modernos. Los antiguos no tenían ninguna «soberanía» que limitar ni, sobre todo, habían pensado jamás en la constitución como norma, la norma que en el tiempo moderno sería llamada a separar los poderes y a garantizar los derechos. Ellos pensaban mas bien en la constitución como en una exigencia a satisfacer, como en un ideal - al mismo tiempo ético y político - a perseguir, que se hacía todavía mas fuerte -como hemos visto - en las fases de crisis mas intensa, de mas clara separación política y social, como en el caso de la decadencia de la polis griega o de la misma republica romana" (FIORAVANTI, Maurizio - Op. cit., p. 29).

11 No ambiente de direito natural, recupera-se a leitura dos clássicos tanto o racionalismo naturalista aristotélico (concebido principalmente na obra, "Ética à Nicômaco") como do estoicismo ciceroniano (presente no livro De Officiis - "Dos Deveres"). 
reminiscência ao exercício do direito de defesa numa leitura moderada pela questão: é a guerra justa?

Dentre as várias vertentes, Hugo Grotius, numa leitura de direito natural justificado no direito divino de raiz cristã e no historicismo romano de transposição de premissas do jus naturale e do jus ciuillis para concepção do jus voluntarium que fundamentasse um "direito das nações", determinado pelo consentimento geral e pela lei da natureza ${ }^{12}$, definiu a guerra como o estado dos indivíduos que eliminam [rectius, esvaziam] suas diferenças pela força considerada como tal ${ }^{13}$, cuja origem adviria em última instância de duellum enquanto indicativo de desunião, a que a paz ${ }^{14}$, ao contrário, induziria a união ${ }^{15}$.

Grotius esclarece que não se preocupou em definir justiça, senão de identificar se alguma guerra seria justa, e qual guerra seria justa ${ }^{16}$. Portanto, a acepção de direito na expressão "direito da guerra" que forma o título da obra de 1625 - "Direito da Guerra e Direito da Paz" -, indica o interesse na investigação para saber se haveria alguma guerra justa, e, mais, o quê haveria de justo na guerra, de sorte que "direito é o que não é injusto", cujo sentido de injusto é "aquilo que é repugnante à natureza da sociedade de seres dotados de razão"17.

A tensa oposição entre guerra e paz pelos olhos da justiça numa perspectiva de direito natural de raiz religiosa pode ser percebida nos Tratados de Paz de Vestefália, restritos ${ }^{18}$ ao Tratado de Munster, de 31 de janeiro de 1648, firmado entre o Reino da Espanha e dos Estados-Gerais das Províncias Unidas dos Países Baixos; ao Tratado de Munster, de 24 de

12 HERSHEY, A. - History of International Law Since the Peace of Westphalia. In American Journal of International Law. Buffalo. ISSN 0002-9300. V. 6, N. ${ }^{\circ}$ 1, 1912, p. 32.

13 Tradução livre e pessoal de: “[...] la guerre est l’état d'individus qui vident leurs différends par la force, considerés comme tels [...]" (GROTIUS, Hugo - Le Droit de la Guerre et de la Paix. Tradução ao francês: M. P. Pradier-Fodéré - Tomo I. Paris: Librairie de Guillaumin et Cie., 1867, p. 61).

14 Ao término do Livro III da obra, Le Droit de la Guerre et de la Paix, Grotius (1867, tomo III, p. 471) afirma que "Mas a paz feita, sob quaisquer condições, deve ser plenamente observada, por causa desta santidade de fé, da qual falamos, e devemos evitar com atenção, não apenas perfídia, mas também tudo o que irrita os espíritos", tradução livre e pessoal de: "Mais la paix faite, à quelques conditions que ce soit, doit être pleinement observée, à cause de cette sainteté de la foi, dont nous avons parlé, et l'on doit éviter avec vigilance, non-seulement la perfidie, mais aussi tout ce qui irrite les esprits".

15 GROTIUS, Hugo - Le Droit de la Guerre et de la Paix. Tradução ao francês: M. P. Pradier-Fodéré - Tomo I. Paris: Librairie de Guillaumin et Cie., 1867, p. 62.

16 GROTIUS, Hugo - Le Droit de la Guerre et de la Paix. Tradução ao francês: M. P. Pradier-Fodéré - Tomo I. Paris: Librairie de Guillaumin et Cie., 1867, p. 62.

17 Inspiração em: "Car le mot droit ne signifie autre chose ici que ce qui est juste, et cela dans un sens plutôt négatif qu'affirmatif, de sorte que le droit est ce qui n'est pas injuste. Or, ce qui est injuste c'est ce qui répugne à la nature de la société des êtres doués de raison" (GROTIUS, Hugo - Le Droit de la Guerre et de la Paix. Tradução ao francês: M. P. Pradier-Fodéré - Tomo I. Paris: Librairie de Guillaumin et Cie., 1867, p. 62).

18 A dita restrição se refere, em função da natureza exemplificativa dos tratados, aos instrumentos firmados em 1648, excluindo-se qualquer outro por mais importante que seja, como é o caso do Tratados dos Pirineus firmado em 07 de novembro de 1659 entre o Reino da França e o Reino de Espanha (Disponível em: <http://mjp.univ-perp. fr/traites/1659pyrenees.htm>, último acesso em 30/05/2019). 
outubro de 1648, assinado entre o Sacro Império Romano Germânico e o Reino da França; e ao o Tratado de Osnabruck, de 24 de outubro de 1648, realizado entre o Sacro Império Romano Germânico e o Reino da Suécia

Neste sentido, o Tratado de Munster (31/01/1648) determinou o fim da longa e sangrenta guerra entre o Reino da Espanha e dos Estados-Gerais das Províncias Unidas dos Países Baixos por inspiração da compaixão cristã e desejo de expungir as calamidades públicas, danos, inconvenientes e perigos advindos dos atos hostis, dando lugar aos efeitos muito agradáveis de uma boa e sincera pacificação que permitisse, aos povos e aos Estados, pela Graça Divina, recuperar as ruínas e cessar a desordem, motivando-se uma paz perpétua que se pretendia fosse boa, firme, fiel e inviolável (preâmbulo, Art. I, e Art. II) ${ }^{19}$.

Na mesma seara, o Tratado de Munster (24/10/1648) ao conceber a cessação da longa e cruel guerra entre o Sacro Império Romano Germânico e o Reino da França com seus aliados para instauração de uma paz cristã e universal ilustrada por uma amizade perpétua, sincera e verdadeira (preâmbulo, e Art. I) ${ }^{20}$.

E, ainda, o Tratado de Osnabruck (24/10/1648) dedicado ao término da guerra dura e longa entre o Sacro Império Romano Germânico e o Reino da Suécia, possibilitado pela bondade divina e o engajamento racional na busca da paz que cessasse o derramamento de sangue cristão e a desolação de inúmeras províncias; paz, esta, que pretendia fosse cristã, universal e perpétua, ilustrada pela verdadeira e sincera amizade (preâmbulo, e Art. I) ${ }^{21}$.

No século XVIII, Immanuel Kant, ao publicar o opúsculo "A paz perpétua: um projeto filosófico", põe em causa o direito da guerra sob os auspícios da justiça ${ }^{22}$, tanto por não reconhecer uma coação externa oponível por um ente superior aos Estados lançados ao

19 Disponível em: <http://mjp.univ-perp.fr/traites/1648pb.htm>, último acesso em 30/05/2019.

20 Disponível em: <http://avalon.law.yale.edu/17th_century/westphal.asp >, último acesso em 30/05/2019.

21 Disponível em: <http://mjp.univ-perp.fr/traites/1648osnabruck.htm>, último acesso em 30/05/2019.

22 Há, aqui, uma crítica direta a posição de Grotius: "Tendo em conta a maldade da natureza humana, que se pode ver às claras na livre relação dos povos (ao passo que no Estado legal-civil se oculta através da coacção do governo) é, sem dúvida, de admirar que a palavra direito não tenha ainda podido ser expulsa da política da guerra como pedante, e que nenhum Estado tenha ainda ousado manifestar-se publicamente a favor desta última opinião; pois persiste-se ainda a citar candidamente Hugo Grócio, Pufendorf, Vatel e outros (incômodos consoladores apenas!). Embora o seu código elaborado filosófica ou diplomaticamente não tenha a mínima força legal nem a possa também ter (pois os Estados enquanto tais não estão sob nenhuma coacção exterior comum) para a justificação de um ataque bélico, sem que exista um exemplo de que alguma vez um Estado tenha abandonado os seus propósitos em virtude dos argumentos reforçados com os testemunhos de tão importantes homens, esta homenagem que todos os Estados prestam ao conceito de direito (pelo menos, de palavra) mostra que se pode encontrar no homem uma disposição moral ainda mais profunda, se bem que dormente na altura, para se assenhoriar do princípio mau que nele reside (o que não pode negar) e para esperar isto também dos outros; pois, de outro modo, a palavra direito nunca viria à boca dos Estados que se querem guerrear entre si, a não ser para com ela praticarem a ironia como aquele príncipe gaulês, que afirmava: «A vantagem que a natureza deu ao forte sobre o fraco é que este deve obedecer àquele.»" (Kant, 2016, p. 144). 
Da inversão do paradigma teórico-prático até a atual concepção da paz como requisito vital...

ALEX SANDER XAVIER PIRES

GALILEU - e-ISSN 2184-1845 - Volume XX - Issue Fascículo 1 - $1^{\text {st }}$ January Janeiro - 30 th June Junho $2019 \cdot$ pp. 78-98

conflito $^{23}$, tanto por entender que o conceito de justiça é vago e posto unilateralmente pelo vencedor ao vencido nos amplos limites concebidos pela maldade humana ${ }^{24}$.

A proposta kantiana, concebida sobre a ideia de que a paz "significa o fim de todas as hostilidades" 25 , incita a instauração da federação da paz com a missão de "manter e garantir a paz de um Estado para si mesmo, e, ao mesmo tempo, a dos outros Estados federados, sem que estes devam por isso submeter-se a leis públicas e à sua coacção"26, distinguindo-se, portanto, dos pactos de paz - especialmente os tratados - enquanto instrumento paliativos de cessação das guerras mas nunca do esgotamento do estado de guerra ${ }^{27}$.

A ideia de formação de uma associação de Estados dedicada a cessação do estado de guerra e instauração de um estado de paz foi implementada na primeira parte do Tratado de Versalhes ${ }^{28}$ que pôs fim as hostilidades da Primeira Guerra Mundial, com a criação da Liga das Nações, cuja finalidade era de promover a cooperação entre as nações e alcançar a paz e a segurança internacionais mediante: a) a aceitação de não recorrer à guerra; b) a assunção de relações abertas, retas e honradas entre as nações; c) a compreensão do direito internacional como a efetiva regra de conduta entre os governos; e, d) a manutenção da justiça e do respeito escrupuloso por todas as obrigações constantes do tratado nas relações dos povos organizados entre si.

\section{Concepção moderna}

A criação da Liga das Nações ao término da Primeira Guerra Mundial não foi suficiente para instaurar o estado de paz assentado na cessação permanente das hostilidades entre as nações, o que se percebe com o início da Segunda Guerra Mundial.

Neste âmbito, em 1941, pelas resoluç̧̃es constantes do Acordo de St. James ${ }^{29}$, percebe-se o recrudescer da ideia de associação dos Estados soberanos, agora sob a concepção de povos livres, para, reunidos e convergidos ao firme propósito de perseguir a paz duradoura mediante a cooperação voluntária entre si, combaterem a coação pela violência incluindo a ameaça de agressão assentando o estado de segurança, econômica e social, livre de ameaças,

23 KANT, Immanuel - A Paz Perpétua e Outros Opúsculos. Tradução: Artur Morão. Lisboa: Edições 70, 2016 , p. 144.

24 Idem, p. 146.

25 Idem, p. 130.

26 Idem, p. 146.

27 "[...] dado que pelo tratado de paz se põe fim a uma guerra determinada, mas não ao estado de guerra (possibilidade de encontrar um novo pretexto para a guerra, a qual também não se pode declarar como justa, porque em tal situação cada um é juiz dos seus próprios assuntos)" (KANT, Immanuel - Op. cit., p. 145).

28 Disponível em: <http://www.loc.gov/law/help/us-treaties/bevans/m-ustooooo2-0043.pdf>, último acesso em 30/05/2019.

29 Disponível em: <http://avalon.law.yale.edu/imt/imtjames.asp>, último acesso em 30/05/2019. 
que, desde a Carta do Atlântico ${ }^{30}$ deveria incidir sobre a redução da força bélica mediante políticas internacionais de desarmamento concebidas num sistema geral de segurança.

Com inspriação nos princípios da Carta do Atlântico ${ }^{31}$, em 1942, publicou-se a Declaração pelas Nações Unidas em que os vinte e seis Estados signatários originários ${ }^{32}$ comprometeram-se em somar esforços, militares e econômicos, em cooperação para por fim a guerra em vias de defender a vida, a liberdade, a independência e a liberdade religiosa, bem como preservar os direitos humanos e a justiça, para si e para os demais territórios.

A Declaração pelas Nações Unidas levou à Declaração de Moscou sobre a segurança geral $^{33}$ reconhecendo a necessidade de, rápida e ordenadamente, acabar com a guerra e instaurar a paz com o mínimo de dispêndio possível de recursos humanos e econômicos, e, desde então, estabelecer e manter a paz e a segurança internacionais.

Para tanto, dever-se-ia estabelecer, o mais rapidamente possível, uma organização internacional geral aberta à participação de todos os Estados, grandes e pequenos, para a manutenção da paz e da segurança internacionais, com base no princípio da igualdade soberana de todos os Estados amantes da paz (art. $4^{\circ}$ ), que, desde a cessação das hostilidades da Segunda Guerra Mundial, deveriam atuar em cooperação mediante consultas, prévias e recíprocas, especialmente para re-estabelecimento do direito e da ordem (art. $\left.5^{\circ}\right)$, com restrição ao uso da força militar apenas para manutenção dos propósitos da segurança geral, mediante consulta aos demais Estados e em operação conjunta com a comunidade de nações (art. $6^{\circ}$ ), tendo em vista a aproximação de todos para regulamentação do uso de armamento (art. $7^{\circ}$ ).

A Declaração de Moscou sobre a segurança geral assentou as bases para as Conversas de Dumbarton Oaks ${ }^{34}$, ocorridas em 1944, que convergiu a apresentação da Proposta para Estabelecimento da Organização Internacional Geral a ser denominada de Nações Unidas e regulamentada por sua Carta própria baseada nos firmes propósitos da persecução da paz e da segurança internacionais possível pela instauração de mecanismos que afastassem as ameaças de agressão e outros expedientes contra a paz mediante a concepção de meios pacíficos e ajustados para solução das disputas entre os Estados, bem como o desenvolvi-

30 Disponível em: <http://avalon.law.yale.edu/wwii/atlantic.asp>, último acesso em 30/05/2019.

31 Disponível em: <https://www.unmultimedia.org/searchers/yearbook/page.jsp?volume=1946-47\&page=36\&sear chType $=$ advanced $>$, último acesso em 30/05/2019.

32 Até 1945 aderiram mais vinte e um Estados.

33 Disponível em: <https://www.unmultimedia.org/searchers/yearbook/page.jsp?volume=1946-47\&page=38>, último acesso em 30/05/2019.

34 Disponível em: <https://www.unmultimedia.org/searchers/yearbook/page.jsp?volume=1946-47\&page=39\&sear chType=advanced $>$, último acesso em 30/05/2019. 
Da inversão do paradigma teórico-prático até a atual concepção da paz como requisito vital...

ALEX SANDER XAVIER PIRES

GALILEU - e-ISSN 2184-1845 - Volume XX - Issue Fascículo 1 - $1^{\text {st }}$ January Janeiro - 30 th June Junho $2019 \cdot$ pp. 78-98

mento de relações amigáveis entre as nações que favorecesse o fortalecimento de uma paz universal.

As Conversas de Dumbarton Oaks foram sucedidas pelo Acordo de Yalta ${ }^{35}$ que, para além de resolver a questão do procedimento de votação e confirmação da decisão de estabelecimento breve da organização internacional geral para instauração e manutenção da paz e da segurança internacionais, reafirmou a necessidade de colaboração estreita e contínua de todos os povos amantes da paz, tanto para impedir a agressão como para eliminar as causas políticas, econômicas e sociais da guerra.

\section{Carta das Nações Unidas: fundamentos, propósitos e princípios inspiradores do sistema de paz}

Em 26 de junho de 1945, como conclusão da Conferência das Nações Unidas sobre Organização Internacional (Conferência de San Francisco), foi assinada a Charter of the United Nations (Carta das Nações Unidas ${ }^{36}$ ), composta por cento e onze artigos distribuídos em dezenove capítulos, cuja vigência se deu a partir de 24 de outubro de 1945; a que se integra o Estatuto da Corte Internacional de Justiça com setenta artigos sistematizados em cinco capítulos.

O Preâmbulo da Carta inicia por reconhecer o paradigma humanitário e associativo quando trás ao debate a reunião de povos - não de Estados em relação fenomenológica de poder - com o fim uníssono de manutenção da paz e da segurança internacionais que obstassem novas guerras de proporções mundiais, num ambiente de confiança nos direitos fundamentais, na igualdade ampla e irrestrita entre todos, na dignidade e no valor, sempre centrados no ser humano, independentemente da nação em que estivesse.

Por esta orientação, a Carta das Nações Unidas determina como finalidade: a) preservação das gerações futuras do flagelo da guerra; b) reafirmação dos direitos fundamentais, da dignidade do ser humano, e da igualdade de direitos ${ }^{37}$; c) estabelecimento de condições para a concretização da justiça, e de bases para o respeito às obrigações decorrentes de tratados e de outras fontes de direito internacional; e, d) promoção, inspirada pelo princípio da liberdade mais ampla, para o progresso social, e para melhores condições de vida.

Outrossim, são mecanismos antevistos na Carta para consecução destas finalidades: a) prática da tolerância; b) convívio em paz por inspiração das práticas de boa vizinhança;

35 Disponível em: <https://www.unmultimedia.org/searchers/yearbook/page.jsp?volume=1946-47\&page=44\&sear chType=advanced $>$, último acesso em 30/05/2019.

36 Disponível em: <http://dag.un.org/bitstream/handle/11176/387353/PORTUGUESE-1976. pdf? sequence $=1$ \&isAllowed $=\mathrm{y}>$, último acesso em 30/05/2019.

37 Igualdade de direitos, tanto dos homens entre si (leia-se, também, entre homens e mulheres), como das nações, grandes e pequenas. 
c) busca da manutenção da paz; d) persecução da segurança internacional; e) reconhecimento, em nível de garantia, de uso consciente e limitado das forças armadas; e, f) emprego de mecanismos internacionais para promoção do progresso econômico e social de todos os povos.

No âmbito dos propósitos, determina a Carta das Nações Unidas: a) a manutenção da paz e da segurança, internacionais ${ }^{38}$ (art. 1, 1, primeira parte); b) o desenvolvimento das relações amistosas entre as nações em vias de fortalecer a paz universal ${ }^{39}$ (art. 1, 2, primeira parte); c) a consecução da cooperação internacional para resolução dos problemas de caráter econômico, social, cultural, ou humanitário (art. 1, 3, primeira parte); d) a consecução da cooperação internacional para promoção e estímulo do respeito aos direitos humanos para todos, sem distinção de raça, sexo, língua ou religião (art. 1, 3, segunda parte); e) a consecução da cooperação internacional para promoção e estímulo do respeito às liberdades fundamentais para todos, sem distinção de raça, sexo, língua ou religião (art. 1, 3, terceira parte); e, f) a assunção de "centro destinado a harmonizar a ação das nações para a consecução" dos objetivos comuns (art. 1, 4).

Ademais, as Nações Unidas, além de coactar os Estados não Membros a observância dos preceitos para manutenção da paz e da segurança internacionais (art. 2,6) e garantir a não intervenção ou a obrigação de submissão em assuntos concernentes aos interesses essencialmente da jurisdição dos Membros (art. 2, 7), prevê como princípios, sem prejuízo de outros: a) igualdade de todos os seus membros (art. 2, 1); b) boa-fé no cumprimento das obrigações assumidas no âmbito da Carta (art. 2, 2); c) resolução pacífica das controvérsias internacionais (art. 2,3); d) vedação a prática da ameaça, nas relações internacionais, entre Estados (art. 2, 4, primeira parte); e) vedação do uso da força "contra a integridade territorial ou a independência política de qualquer Estado" (art. 2, 4, segunda parte); f) vedação de práticas incompatíveis com os propósitos das Nações Unidas (art. 2, 4, in fine); g) prestação de assistência em qualquer ação tomada em função da Carta (art. 2, 5, primeira parte); e, h) abstenção de prestar auxílio a qualquer Estado que esteja sobre interferência, preventiva ou coercitiva, das Nações Unidas (art. 2, 5, in fine).

38 Para manutenção da paz e da segurança internacionais deve-se "tomar, coletivamente, medidas efetivas para evitar ameaças à paz e reprimir os atos de agressão ou outra qualquer ruptura da paz e chegar, por meios pacíficos e de conformidade com os princípios da justiça e do direito internacional, a um ajuste ou solução das controvérsias ou situações que possam levar a uma perturbação da paz" (art. 1, 1, in fine)

39 Para o desenvolvimento das relações amistosas entre as nações em vias de fortalecer a paz universal, consignou-se o "respeito ao princípio da igualdade de direitos e de autodeterminação dos povos", além de outras medidas apropriadas (art. 1, 1, in fine). 


\section{Sistema de paz e a Assembleia Geral das Nações Unidas ${ }^{40}$ em quatro passos}

Longe de encerrar o sistema de paz, a Carta das Nações Unidas deflagrou a árdua tarefa de formação da consciência individual possibilitada pelo amadurecimento moral baseado na constante e perpétua manutenção da paz e da segurança internacionais num ambiente de cooperação, diálogo e respeito, por seres humanos, povos, nações e Estados, cuja hercúlea missão em nível coletivo coube a Assembleia Geral.

Nesta seara, propõe-se a análise, em quatro passos, do sistema de paz das Nações Unidas concebido: a um, pelo assentamento das bases para a concepção do sistema com restrição temporal nos cinco primeiros períodos de sessões, mormente entre o terceiro e o quinto (A/RES/3/19o; A/RES/3/217; A/RES/4/290; A/RES/5/377; A/RES/5/380; A/RES/5/381; e, $\mathrm{A} / \mathrm{RES} / 5 / 494)$ ) a dois, pela instauração da cultura de paz (A/RES/53/243; A/RES/33/73; e, A/ RES/39/11); a três, pela declaração sobre o direito à paz (A/RES/71/189); e, a quatro, pela promoção da paz como requisito vital para o pleno desfrute dos direitos humanos para todos (A/RES/33/170).

\section{A. 70 anos desde o início da concepção do sistema}

A quebra do paradigma anterior impôs um período de adaptação ao novo sistema de paz introduzido pela Carta das Nações Unidas que alçara a paz e segurança internacionais ao nível de Propósito para toda a Humanidade, em nível de povos em coletividade de seres humanos e em igualdade, mas também por nações pequenas e grandes, e por representação política dos Estados (veja-se: ser humano, povo, nação e Estado). Assim, os cinco primeiros períodos de sessões da Assembleia Geral serviram a formação [rectius, adequação] das bases dos sistema de paz.

Importante passo foi dado no $3 .{ }^{\circ}$ Período de Sessões da Assembleia Geral das Nações Unidas ocorrido entre 1948 e 1949, tanto pela A/RES/3/190 (Apelo às grandes potências para renovação dos esforços para compor suas diferenças e estabelecerem a paz definitiva) como pela A/RES/3/217 (Carta Internacional dos Direitos do Homem, que, introduziu, em cinco partes a Declaração Universal dos Direitos do Homem [A/RES/3/217(A)], o Direito de Petição [A/RES/3/217(B)], o Destino das Minorias [A/RES/3/217(C)], a Publicidade a ser dada a Decla-

40 A Assembleia Geral é um dos principais órgãos das Nações Unidas (Carta, art. 7) formada pela representação, com no máximo cinco representantes (Carta, art. 9, 2), de todos os membros (Carta, art. 9, 1), cuja regulamentação está prevista entre os artigos 9 e 22.

41 Disponível em: <https://www.un.org/en/ga/search/view_doc.asp?symbol=A/RES/19o(III)>, último acesso em 30/05/2019.

42 Disponível em: <https://www.un.org/en/ga/search/view_doc.asp?symbol=A/RES/217(III)>, último acesso em 30/05/2019. 
ração Universal dos Direitos Humanos [A/RES/3/217(D)], e a Preparação de um Projeto de Pacto Relativo aos Direitos Humanos e das Medidas de Implementação [A/RES/3/217(E)] ).

A A/RES/3/19o, dentre outras disposições, preocupou-se em: a) criar a consciência para acabar definitivamente com as hostilidades da Segunda Guerra Mundial mediante a conclusão e início de cumprimento dos tratados de paz; b) perseguir os firmes propósitos de instauração da paz e da manutenção da segurança internacionais, instando as potências vencedoras a aplicarem, na prática, a deliberação aprovada em teoria; c) convocar os membros a resolução das diferenças e tensões no âmbito das Nações Unidas por ter como função principal, inspirada pela cooperação e pela ajuda mútua entre os povos e nações, a composição dos elementos que possam atentar contra a paz e a segurança; e, d) reafirmar, principalmente, a Declaração de Yalta e a Carta do Atlântico.

A Declaração Universal dos Direitos do Homem, no âmbito da Carta Internacional dos Direitos Humanos (A/RES/3/217) e restrita a paz, pende a reconhecer a dignidade humana e os direitos iguais e inalienáveis como fundamento da paz no mundo (Preâmbulo), além de aproximar à educação qualificada em nível de instrução $0^{43}$ tendente a contribuir com a compreensão, a tolerância e a amizade entre as nações e seres humanos ${ }^{44}$ (art. XXVI, 2).

O 4. ${ }^{\circ}$ Período de Sessões da Assembleia Geral das Nações Unidas ocorrido entre 1949 e 1950 foi marcado pela A/RES/4/29045 (Fundamentos da paz) que contém, dentre os treze dispositivos, a declaração do art. $1 .^{\circ}$ que se divide em quatro pontos: a um, determina a Carta das Nações Unidas como o Pacto de Paz mais solene da História; a dois, esclarece que a Carta das Nações Unidas estabelece os princípios básicos para a paz duradoura; a três, alerta que a desconsideração destes princípios é a principal responsável pela continuação da tensão internacional; e, a quatro, orienta que é urgentemente imprescindível que os Membros adotem os princípios, e sigam-nos, em respeito ao espírito de cooperação que norteia as relações no âmbito das Nações Unidas.

O 5. ${ }^{\circ}$ Período de Sessões da Assembleia Geral das Nações Unidas ocorrido entre 1950 e 1951 caracterizou-se pela aprovação de quatro resoluções: A/RES/5/377 46 (Unindo[-nos] pela

43 "A instrução será orientada no sentido do pleno desenvolvimento da personalidade humana e do fortalecimento do respeito pelos direitos humanos e pelas liberdades fundamentais. (...)" (art. XXVI, 2, primeira parte).

44 Há, aqui, a ressalva que "a compreensão, a tolerância e a amizade" são tratadas no sentido de adoção "entre todas as nações e grupos raciais ou religiosos" (art. XXVI, 2, segunda parte).

45 Disponível em: <http://www.un.org/en/ga/search/view_doc.asp?symbol=A/RES/29o(IV)>, último acesso em 11/03/2019.

46 Disponível em: <http://www.un.org/en/ga/search/view_doc.asp?symbol=A/RES/377(V)>, último acesso em 12/03/2019. 
paz); A/RES/5/380 47 (Paz por ações); A/RES/5/381 ${ }^{48}$ (Condenação da propaganda contra a paz); e, A/RES/5/494 ${ }^{49}$ (Desenvolvimento do Programa de 20-anos para alcançar a paz através das Nações Unidas).

A A/RES/5/377 (Unindo[-nos] pela paz) distribui o tema em cinco partes em vias de assentar os dois primeiros propósitos da Carta das Nações Unidas ${ }^{50}$ : a) ao considerar a difícil formação da unanimidade no Conselho de Segurança, propôs-se a Emenda a Regra de Procedimento da Assembleia Geral, acompanhada de duas "recomendações ao Conselho de Segurança"; b) propõe a criação da Comissão de Observação da Paz; c) convida cada Membro a analisar e determinar a possível disponibilização de recursos militares a serem postos a serviço das Nações Unidas; d) promove a criação do Comitê de Medidas Coletivas; e, e) renova o interesse no assentamento da consciência que a segurança e a paz definitiva dependem do cumprimento, por todos (principalmente os Membros do Conselho de Segurança), dos Princípios e Finalidades da Carta da Nações Unidas.

A A/RES/5/380 (Paz por ações), em sentido amplo, conclamou a comunidade internacional (Estados e Povos) a partir para ação na persecução da paz e da segurança, mediante o controle de alguns atos/fenômenos (item 2) e da consciência de não intervenção de um Estado em outro, tampouco de abusos no uso do poder público em seu próprio território (item 1).

A A/RES/5/381 (Condenação da propaganda contra a paz) reafirmou as Resoluções A/ $\mathrm{RES} / 2 / 110^{51}$ (Medidas a serem tomadas contra a propaganda e os incitadores de uma nova guerra) e A/RES/4/290 52 (Fundamentos da paz), ao definir os atos vedados e o "sentido" do que vem a ser "propaganda contra a paz".

A A/RES/5/494 (Desenvolvimento do Programa de 20-anos para alcançar a paz através das Nações Unidas) conclama a elaboração do "Memorandum" pela paz de iniciativa do Secretário Geral.

47 Disponível em: <http://www.un.org/en/ga/search/view_doc.asp?symbol=A/RES/38o(V)>, último acesso em 12/03/2019.

48 Disponível em: <http://www.un.org/en/ga/search/view_doc.asp?symbol=A/RES/381(V)>, último acesso em $12 / 03 / 2019$.

49 Disponível em: <http://www.un.org/en/ga/search/view_doc.asp?symbol=A/RES/494(V)>, último acesso em $12 / 03 / 2019$.

50 Lembra-se: manter a paz e a segurança internacionais baseadas nos princípios de justiça e de direito internacional; e, desenvolver as relações amistosas entre as nações com observância aos princípios dos direitos iguais e da autodeterminação dos povos.

51 Disponível em: <http://www.un.org/en/ga/search/view_doc.asp?symbol=A/RES/11o(II)>, último acesso em $12 / 03 / 2019$.

52 Disponivel em: <http://www.un.org/en/ga/search/view_doc.asp?symbol=A/RES/290(IV)>, último acesso em 11/03/2019. 


\section{B. 20 anos da Declaração sobre a Cultura de Paz}

Por ocasião do $53 .^{\circ}$ Período de Sessões, em 1998/1999, aprovou-se a A/RES/53/24353 tanto dedicada, na primeira parte, à Declaração sobre a Cultura de Paz como, na segunda, ao Programa de Ação sobre a Cultura de Paz, que partem da reafirmação da paz e da segurança internacionais como propósito e princípio das Nações Unidas, em nível de Carta, de Declaração Universal dos Direitos do Homem, e dos demais instrumentos que constituíam - e constituem - o sistema de proteção e instauração da paz, como, por exemplo, a Declaração sobre a Preparação das Sociedades para Viver em Paz (A/RES/33/73) $)^{54}$, e a Declaração sobre o Direito dos Povos à Paz (A/RES/39/11) $)^{55}$.

$\mathrm{Na}$ Declaração sobre a preparação das sociedades para viver em paz (A/RES/33/73), foram consignados os seguintes princípios: a) todos, nações e seres humanos, têm o direito imanente de viver em paz, independentemente das particularidades (art. 1); b) o planejamento, a preparação ou o início de uma guerra de agressão ${ }^{56}$ constituem crimes contra a paz e são proibidos pelo direito internacional (art. 2 c/c art. 5, 2 da Resolução n. ${ }^{\circ}$ 29/3314); c) os Estados, de acordo com os propósitos e princípios das Nações Unidas, devem se abster de fazer propaganda a favor das guerras de agressão (art. 3); d) todo Estado, inspirado pela amizade, pelas práticas de boa vizinhança e independentemente de sua condição sócio-econômica particular, deve promover a cooperação, benéfica e equitativa, com outros Estados, nos planos político, econômico, social e cultural (art. 4); e) todo Estado deve respeitar o direito de todos os povos a autodeterminação, a independência, a igualdade, a soberania, a integridade territorial dos Estados e a inviolabilidade de suas fronteiras (art. 5); f) há que se eliminar a ameaça da corrida armamentista, ao mesmo tempo que se deve promover esforços para um desarmamento geral e completo, sob controle internacional (art. 6); g) todo Estado deve desestimular as manifestações e práticas de colonialismo, racismo, discriminação racial e apartheid (art. 7); e, h) todo Estado deve desestimular, igualmente, a promoção do ódio e do preconceito contra outros povos (art. 8).

A Declaração sobre o Direito dos Povos à Paz (A/RES/39/11) registrou o discurso direto sobre a necessidade de se prevenir uma catástrofe nuclear mundial mediante o estabelecimento de uma paz duradoura em todo o planeta, em vias de se preservar a existência e a civilização humana. Assim, este instrumento determina que todos os povos têm o direito

53 Disponível em: <https://www.un.org/en/ga/search/view_doc.asp?symbol=A/RES/53/243>, último acesso em 30/05/2019.

54 Disponível em: <https://www.un.org/en/ga/search/view_doc.asp?symbol=A/RES/33/73>, último acesso em 30/05/2019.

55 Disponível em: <https://www.un.org/en/ga/search/view_doc.asp?symbol=A/RES/39/11>, último acesso em 30/05/2019.

56 Dentre outros dispositivos, a agressão que denota a guerra tem previsão no art. 3 da Resolução n. ${ }^{\circ} 29 / 3314$. 
sagrado à paz (art. 1), de igual modo que impõe a obrigação fundamental de todos os Estados garantirem este direito sagrado (art. 2), mediante a adoção de políticas públicas de eliminação da ameaça da guerra (especialmente a nuclear), da renúncia do uso da força nas relações internacionais, e da resolução pacífica das controvérsias de acordo com a Carta (art. 3).

Ademais, deu seguimento a A/RES/52/15 $5^{57}$ que proclamou o ano de 2000 como "ano internacional para a cultura de paz", e, também, a A/RES $/ 53 / 25^{58}$ que declarou o período de 2001-2010 como a "década para a cultura de paz e não-violência para as crianças do mundo".

Especificamente no âmbito da Declaração sobre uma Cultura de Paz acolhida na A/ RES/53/243, de 06 de outubro de 1999, inspirada e possibilitada pelo término da guerra fria, reconhecem-se três assertivas: a primeira, as guerras nascem na mente dos seres humanos, de forma que é ali que se deve fortalecer a paz (premissa dantes declarada na Constituição da Organização das Nações Unidas para a Educação, a Ciência e a Cultura); a segunda, a percepção que a paz, mais do que a simples ausência de conflito, requer um processo positivo, dinâmico e participativo, de promoção do diálogo em vias de se buscar a solução negociada em um espírito de entendimento e cooperação de todos os atores; e, a terceira, a concreta necessidade de se perquirir a eliminação de todas as formas de discriminação e intolerância.

A justificar as assertivas, a Declaração assume que o sucesso na implementação da cultura de paz somente é possível pela disseminação de valores, atitudes, comportamentos, e estilos de vida dedicados exclusivamente ao fomento da paz entre as pessoas, os grupos e as nações (art. 2); sendo a educação, em todos os níveis e voltada a difusão dos direitos humanos, o meio fundamental para sua edificação (art. 4), enquanto todos devem se comprometer com o seu fortalecimento, ou seja, os governos têm a função primordial de promovê-la (art. 5), a sociedade civil tem o compromisso com o seu desenvolvimento pleno (art. 6), a grande mídia deve contribuir com a difusão da informação qualificada e educativa (art. 7), as Nações Unidas devem seguir com sua missão de desempenhar a função crítica conducente ao fortalecimento do movimento (art. 9), e os pais, professores, políticos, jornalistas, órgãos e grupos religiosos, intelectuais, todos os que realizem atividades científicas, filosóficas, criativas e artísticas, sanitaristas, humanitaristas, diretores de organizações governamentais e não governamentais, a quem assiste a função chave de promover a cultura de paz (art. 8).

57 Disponível em: <https://www.un.org/en/ga/search/view_doc.asp?symbol=A/RES/52/15>, último acesso em 30/05/2019.

58 Disponível em: <https://www.un.org/en/ga/search/view_doc.asp?symbol=A/RES/53/25>, último acesso em 30/05/2019. 
Outrossim, a cultura de paz, enquanto conjunto de valores, atitudes, tradições, comportamentos e estilos de vida se baseia: a) no respeito a vida, no fim da violência, na promoção da prática de não violência por meio da educação, do diálogo e da cooperação (art. 1, a); b) no respeito aos princípios da soberania, da integridade territorial, da independência política dos Estados, e da não interferência nos assuntos eminentemente de jurisdição interna dos Estados (art. 1, b); c) no respeito irrestrito e na difusão dos direitos humanos e das liberdades fundamentais (art. 1, c); d) no compromisso com a solução pacífica de conflitos (art. 1, d); e) no esforço para satisfação das necessidades de desenvolvimento e proteção do meio-ambiente (art. 1, e); f) no respeito e promoção do direito ao desenvolvimento (art. 1, f); g) no respeito e difusão da igualdade de direitos e oportunidades, especialmente entre mulheres e homens (art. 1, g); h) no respeito e promoção do direito de todas as pessoas as liberdades de expressão, de opinião e de informação (art. 1, h); e, i) na adesão aos princípios de liberdade, justiça, democracia, tolerância, solidariedade, cooperação, pluralismo, diversidade cultural, diálogo e entendimento em todos os níveis da sociedade e entre as nações (art. 1, i).

\section{Contemporaneidade: Declaração sobre o Direito à Paz}

Firmadas as bases ideológicas com assento, dentre outros ${ }^{59}$, na Carta das Nações Unidas, na Declaração Universal dos Direitos Humanos, no Pacto Internacional de Direitos Civis e Políticos, no Pacto Internacional dos Direitos Econômicos, Sociais e Culturais, na Declaração sobre o Direito ao Desenvolvimento, na Declaração e no Programa de Ação de Viena, na Preparação das Sociedades para Viver em Paz, na Declaração sobre o Direito dos Povos à Paz, e na Declaração e Programa de Ação sobre uma Cultura de Paz; aprovou-se a Declaração sobre o Direito à Paz (A/RES/71/189 $\left.9^{60}\right)$ concebida em sintéticos cinco artigos.

Sem prejuízo da concepção de todos - nações e seres humanos - terem o direito imanente de viver em paz, independentemente das particularidades (A/RES/33/73, art. 1), e que tal direito é sagrado (A/RES/39/11, art. 1), estendeu-se a interpretação para que acolhesse, também, o desfruto da paz, no sentido de promoção e proteção de todos os direitos humanos e o alcance do desenvolvimento pleno, para todos (A/RES/71/189, art. $1^{61}$ ); o que seria possível com o respeito, a aplicação e a promoção da igualdade e da não discriminação,

59 Por exemplo, a Declaração do Milênio (A/RES/55/2), a Agenda 2030 para o Desenvolvimento Sustentável (A/ RES/70/1), o Documento Final da Cúpula Mundial 2005 (A/RES/6o/1), A Declaração sobre os princípios de Direito Internacional, especialmente os referentes as relações de amizade e de cooperação entre os Estados (A/ RES/25/2625), a Definição de Agressão (A/RES/29/3314), e a Declaração sobre a Concessão da Independência aos Países e Povos Coloniais (A/RES/25/1514).

60 Disponível em: <https://www.un.org/en/ga/search/view_doc.asp?symbol=A/RES/71/189>, último acesso em 30/05/2019.

61 "Artigo 1. Toda pessoa tem o direito de desfrutar da paz de modo que todos os direitos humanos sejam promovidos e protegidos e o desenvolvimento seja plenamente realizado"; tradução livre e pessoal de "Article 1. Everyone 
da justiça e do estado de direito, e da garantia contra o medo e a miséria, sem prejuízo de outros direitos avocados no âmbito da Carta das Nações Unidas, da Declaração Universal dos Direitos Humanos, e de instrumentos internacionais e regionais sobre a temática (A/ RES/71/189, art. $5^{62}$ ), alçados a condição de deveres oponíveis aos Estados (A/RES/71/189, art. $\left.2^{63}\right)$, extensível as Nações Unidas e as agências/órgãos especializados nos limites de suas competências, responsabilidades e atuações (A/RES/71/189, art. 3).

Para cumprimento do dever de garantir o desfruto da paz no ambiente dos direitos humanos e na persecução do pleno desenvolvimento, os Estados, as Nações Unidas e as agências/órgãos especializados devem adotar medidas sustentáveis e adequadas a consecução do múnus; de igual forma que se conclama ao apoio e à assistência das organizações internacionais, regionais, nacionais e locais, bem como à sociedade civil (A/RES/ 71/189, art. $3^{64}$ ). Em todos os casos a educação adequada e inspirada nos valores da tolerância, do diálogo, da cooperação e da solidariedade entre todos os seres humanos, deve servir de instrumento básico para a construção e fortalecimento do direito à paz (A/RES/71/189, art. $4^{65}$ ).

has the right to enjoy peace such that all human rights are promoted and protected and development is fully realized". Disponível em: <http://undocs.org/en/A/RES/71/189>, último acesso em 20/04/2017.

62 "Artigo 2. Os Estados devem respeitar, implementar e promover a igualdade e a não-discriminação, a justiça e o Estado de Direito, e garantir o livramento do medo e da miséria como meio de construir a paz dentro das sociedades e entre elas"; tradução livre e pessoal de "Article 2. States should respect, implement and promote equality and non-discrimination, justice and the rule of law, and guarantee freedom from fear and want as a means to build peace within and between societies". Disponivel em: <http://undocs.org/en/A/RES/71/189>, último acesso em 20/04/2017.

63 "Artigo 5. Nenhuma disposição da presente Declaração será interpretada como contrária aos propósitos e princípios das Nações Unidas. As disposições incluídas na presente Declaração devem ser entendidas de acordo com a Carta das Nações Unidas, a Declaração Universal dos Direitos Humanos e os instrumentos internacionais e regionais relevantes ratificados pelos Estados"; tradução livre e pessoal de "Article 5. Nothing in the present Declaration shall be construed as being contrary to the purposes and principles of the United Nations. The provisions included in the present Declaration are to be understood in accordance with the Charter of the United Nations, the Universal Declaration of Human Rights and relevant international and regional instruments ratified by States". Disponível em: <http://undocs.org/en/A/RES/71/189>, último acesso em 20/04/2017.

64 "Artigo 3. Os Estados, as Nações Unidas e as agências especializadas devem adotar medidas adequadas e sustentáveis para implementar a presente Declaração, em particular a Organização das Nações Unidas para a Educação, a Ciência e a Cultura. As organizações internacionais, regionais, nacionais e locais e a sociedade civil são encorajadas a apoiar e a ajudar na implementação da presente Declaração"; tradução livre e pessoal de "Article 3. States, the United Nations and specialized agencies should take appropriate sustainable measures to implement the present Declaration, in particular the United Nations Educational, Scientific and Cultural Organization. International, regional, national and local organizations and civil society are encouraged to support and assist in the implementation of the present Declaration". Disponivel em: <http://undocs.org/en/A/ RES/71/189>, último acesso em 20/04/2017.

65 "Artigo 4. As instituições internacionais e nacionais de educação para a paz devem ser promovidas a fim de fortalecer entre todos os seres humanos o espírito de tolerância, diálogo, cooperação e solidariedade. Para tal, a Universidade para a Paz deve contribuir para a grande tarefa universal de educar para a paz, através do ensino, da investigação, da formação pós-graduada e da difusão do conhecimento"; tradução livre e pessoal de "Article 4. International and national institutions of education for peace shall be promoted in order to strengthen among all human beings the spirit of tolerance, dialogue, cooperation and solidarity. To this end, the University for 


\section{Promoção da paz como requisito vital para o pleno desfrute dos direitos humanos para todos}

Passados dois anos desde a Declaração sobre o Direito à Paz (A/RES/71/189), o 73. ${ }^{\circ}$ Período de Sessões da Assembleia Geral das Nações Unidas, em 17 de dezembro de 2018, deu por aprovada a A/RES/73/170 $0^{66}$ (Promoção da paz como requisito vital para o pleno desfrute dos direitos humanos para todos), o que o fez em doze disposições apoiadas em densa exposição preambular.

A dita exposição preambular, por agora, pode ser restringida a três justificativas: a um, do necessário cumprimento do objetivo de criar condições de estabilidade e bem-estar, indispensáveis às relações pacíficas e amistosas entre as nações, baseadas no respeito pelos princípios da igualdade de direitos e da autodeterminação dos povos; a dois, a concepção de que a vida sem guerra é o pré-requisito internacional primário para o bem-estar material, desenvolvimento e progresso dos países, bem como para a plena implementação dos direitos e liberdades humanas fundamentais proclamados pelas Nações Unidas; e, a três, a convergente observação de que a cooperação internacional no campo dos direitos humanos contribui para criar um ambiente internacional de paz e estabilidade.

Superadas as restritas justificativas, passa-se ao teor normativo, o que se faz conclamando à disseminação, à compreensão e ao respeito universal da Declaração sobre o Direito a Paz, a todas as associações, especialmente as que compõem o sistema das Nações Unidas $\left(\operatorname{art.} 1^{\circ}\right)$, sob a renovação da ideia que todos os povos do planeta têm o sagrado direito à paz (art. $2^{\circ}$ ) em que a educação tem importância vital como instrumento para promoção deste fim $\left(\operatorname{art.} 10^{\circ}\right)$, bem como que a preservação deste direito e o empenho em sua implementação constitui obrigação fundamental de todos os Estados (art. $3^{\circ}$ ).

Outrossim, em nível amplo de direitos humanos, concebe a paz como requisito vital para a promoção e a proteção de todos estes direitos em igualdade para todos (art. $4^{\circ}$ ), afirmando que todos os Estados devem promover o estabelecimento, a manutenção e o fortalecimento da paz e da segurança internacionais, e insistir na implementação de um sistema internacional baseado no respeito aos princípios consagrados na Carta e na promoção de todos os direitos humanos e liberdades fundamentais, incluindo o direito ao desenvolvimento e o direito dos povos a autodeterminação (art. $7^{\circ}$ ), de igual modo reafirma o dever de todos os Estados, de acordo com os princípios da Carta, de utilizar meios pacíficos para

Peace should contribute to the great universal task of educating for peace by engaging in teaching, research, post-graduate training and dissemination of knowledge". Disponivel em: $\langle$ http://undocs.org/en/A/RES/71/189>, último acesso em 20/04/2017.

66 Disponível em: <https://www.un.org/en/ga/search/view_doc.asp?symbol=A/RES/73/170>, último acesso em 30/05/2019. 
Da inversão do paradigma teórico-prático até a atual concepção da paz como requisito vital...

resolver qualquer litígio que o envolva e cuja continuação seja suscetível de pôr em perigo a manutenção da paz e segurança internacionais, como requisito vital para a promoção e proteção de todos os direitos humanos de todos os seres humanos e de todos os povos (art. $9^{\circ}$ ). Para tanto, convida os Estados e os mecanismos e procedimentos relevantes dos direitos humanos das Nações Unidas a continuar atentos à importância da cooperação, compreensão e diálogo mútuos para assegurar a promoção e proteção de todos os direitos humanos $\left(\operatorname{art.} 11^{\circ}\right)$.

No âmbito dos compromissos em sentido estrito, destaca que: a) o abismo sempre crescente que divide, ricos e pobres, mundos desenvolvido e em desenvolvimento, marca a maior ameaça a prosperidade global, a paz e segurança, e a estabilidade (art. $5^{\circ}$ ); b) a preservação e a promoção da paz exigem que as políticas dos Estados sejam direcionadas para a eliminação da ameaça de guerra, particularmente a guerra nuclear, a renúncia ao uso ou ameaça de uso da força nas relações internacionais e a resolução das disputas internacionais pelos meios pacíficos com base na Carta das Nações Unidas (art. $6^{\circ}$ ); e c) todos os Estados devem respeitar e pôr em prática os propósitos e princípios da Carta nas suas relações com outros Estados, independentemente do seu sistema político, econômico ou social e da sua dimensão, localização geográfica ou nível de desenvolvimento econômico (art. $8^{\circ}$ ).

\section{Conclusões}

A análise finda sobre a contemporaneidade do discurso normativo das Nações Unidas sobre os seus quatro passos do sistema de paz, partindo da inversão do paradigma teórico-prático concebido no âmbito da "constituição dos modernos" até a atual concepção da paz como requisito vital para o pleno desfrute dos direitos humanos em igualdade para todos, permite as seguintes conclusões:

1. Não mais se admite em tempos modernos a restrita acepção de paz como mero direito oposto à guerra, no sentido de compor uma dualidade tensa justificada numa matriz imprecisa como a justiça.

2. Outrossim, não se admite a restrição a simples cessação das hostilidades por se conceber que o estado de paz não encerra todo o interesse em constituir as sólidas bases da paz permanente, universal e constante.

3. Ao contrário, atualmente perquire-se incutir na consciência humana, como amadurecimento moral, a ideia de que a paz, para além da cessação de todas as hostilidades, indica um estado permanente, universal e perpétuo, que deve acompanhar os seres humanos nas relações entre si. 
4. O dito amadurecimento moral consciente deve ser transposto em nível de Estados e reverberar para a colaboração estreita e contínua para eliminação definitiva das causas políticas, econômicas e sociais da guerra; e, porque não dizer, para encerrar quaisquer divergências e tensões mediante o diálogo e o respeito.

5. A colaboração internacional deve ser prestada em nível de seres humanos, povos, nações e Estados, por inspiração na rígida busca da paz e segurança para todos.

6. Incumbe às Nações Unidas, enquanto grande palco internacional para aproximação de povos e de Estados, promover a colaboração e, mais, a formação da "consciência pela paz"; e é o que se vê desde o terceiro até o septuagésimo terceiro Período de Sessões da Assembleia Geral.

7. Para o cumprimento desta missão, permite-se antever quatro passos para o fortalecimento do sistema de paz, desde a sua concepção (A/RES/3/190; A/RES/3/217; A/ RES/4/290; A/RES/5/377; A/RES/5/380; A/RES/5/381; e, A/RES/5/494), passando pela Declaração sobre a Cultura de Paz (A/RES/53/243) que admite a Declaração sobre o Direito à Paz (A/RES/71/189) até desaguar na promoção da paz como requisito vital para o pleno desfrute dos direitos humanos para todos (A/RES/73/170).

8. No sistema, todos - seres humanos, povos, nações e Estados - têm o direito imanente de viver em paz independentemente das particularidades, sendo tal direito sagrado a incluir o próprio desfrute, no sentido de promoção e proteção de todos os direitos humanos e o alcance do desenvolvimento pleno, para todos.

9. A atual Agenda, no âmbito do $73 .{ }^{\circ}$ Período de Sessões acresceu a premissa que todos têm o direito sagrado, a incluir o desfrute, de viver em paz independentemente das particularidades, a previsão que a sua preservação e o empenho na implementação constituem obrigação fundamental de todos os Estados.

\section{REFERÊNCIAS BIBLIOGRÁFICAS}

FIORAVANTI, Maurizio - Constitución: De la Antigüedad a Nuestros Días. Madrid: Editorial Trotta, 2001. GROTIUS, Hugo - Le Droit de la Guerre et de la Paix. Tradução ao francês: M. P. Pradier-Fodéré - Tomo I.

Paris: Librairie de Guillaumin et Cie., 1867.

GROTIUS, Hugo - Le Droit de la Guerre et de la Paix. Tradução ao francês: M. P. Pradier-Fodéré - Tomo III.

Paris: Librairie de Guillaumin et Cie., 1867.

HERSHEY, A. - History of International Law Since the Peace of Westphalia. In American Journal of International Law. Buffalo. ISSN 0002-9300. V. 6, N. ${ }^{0}$ 1, 1912, pp. 30-69.

KANT, Immanuel - A Paz Perpétua e Outros Opúsculos. Tradução: Artur Morão. Lisboa: Edições 70, 2016. PIRES, Alex Sander Xavier - Cultura de Paz e Diálogo no Âmbito da Cooperação entre as Religiões na Contenção do Extremismo que leva ao Terrorismo. Cadernos do Programa de Pós-Graduação em Direito/UFRGS. Porto Alegre. ISSN 1678-5029. V. 12, N. ${ }^{\circ}$ 2, 2017, pp. 73-88. 
PIRES, Alex Sander Xavier - Fluxos migratórios forçados e cultura de paz: um contributo hipotético baseado na educação como pilar da democracia e na solução alternativa à crise do estado assistencialista. In Galileu - Revista de Direito e Economia. Lisboa. ISSN 2184-1845. V. XIX, N. ${ }^{\circ}$ 1, 2018, p. 66-87.

PIRES, Alex Sander Xavier - O terrorismo no âmbito do Direito à Paz. Revista de Direito da ESA/Barra da Tijuca. Rio de Janeiro. ISSN 2558-2081. V. 1, Número especial, 2017, pp. 15-38.

PIRES, Alex Sander Xavier; TRINDADE, Carla Dolezel; FILHO, Simão Aznar - Constitucionalismo Luso-Brasileiro: leitura normativa no âmbito do domínio da lei e da humanização das relações. Rio de Janeiro: Pensar a Justiça, 2017. 